\title{
Mathematical Modeling of Wet Magnesia Flue Gas Desulphurization Process
}

\author{
M. K. Mondal \\ Department of Chemical Engineering and Technology, Institute of Technology, Banaras Hindu University, \\ Varanasi 221005, Uttar Pradesh, India
}

Correspondence should be addressed to M. K. Mondal, mkmondal@bhu.ac.in

Received 3 November 2007; Accepted 28 January 2008

Recommended by F. Gao

\begin{abstract}
Desulphurization of flue gases from various chemical industries in a techno-econo-enviro manner is a demanding technology. The concentrations of sulphur dioxide in and around these plants overshoot the danger point. In recent years, the process analysis of chemical absorption in a slurry has become important in rational design and development of wet scrubbing processes for the removal of $\mathrm{SO}_{2}$ from flue gases. The elementary steps encountered in wet scrubbing by slurries are diffusion and reaction of gaseous species and solid dissolution in liquid film. In the present work, the process of the absorption of sulphur dioxide into wet magnesia slurry was theoretically analyzed according to the two-reaction plane model incorporating the solid dissolution promoted by the reactions with absorbed sulphur dioxide in the liquid film. A model based on Fick's second law has been developed to calculate enhancement factor for absorption of Sulphur dioxide into $\mathrm{Mg}(\mathrm{OH})_{2}$ slurry. The concentration of accumulated species in the bulk of the liquid phase (sulphite ions for this case) which substantially control the absorption rates was included in the model for the prediction of theoretical enhancement factor. The values of theoretical enhancement factors obtained from model were compared with experimental enhancement factors available in literature. The model values of enhancement factors agreed well with the values of experimental enhancement factor available in literature.
\end{abstract}

Copyright (c) 2008 M. K. Mondal. This is an open access article distributed under the Creative Commons Attribution License, which permits unrestricted use, distribution, and reproduction in any medium, provided the original work is properly cited.

\section{INTRODUCTION}

It has long been known that besides being a hazard to human health, emission of sulphur dioxide contributes to the acidification of soil and waterways. Sulphur dioxide has also been reported to support the reactions which create ozone depletion in the stratosphere. Many countries have therefore adapted strict regulations regarding $\mathrm{SO}_{2}$ emissions from coal and oil fired boilers which are one of the primary sources of $\mathrm{SO}_{2}$ emissions. Many different methods are available in the market for reducing the emissions of $\mathrm{SO}_{2}$ from coal and oil fired boilers [1]. The dominating flue gas desulphurization (FGD) technology is based on wet scrubbing specially slurry scrubbing [2].

Slurry reactions have a widespread application in chemical and biochemical industries [3]. The gas absorption with chemical reaction in a slurry containing fine particles has become important in the development of processes for the removal of acidic pollutants. At present, most wet scrubbing processes for the removal of $\mathrm{SO}_{2}$ are by lime and limestone slurry. The major disadvantage of lime/limestone slurry processes is the problem of disposal of calcium sulphate sludge. Wet magnesia FGD system can eliminate scrubber sludge disposal problem and also provide saleable byproduct. In India, most of the sulphur is imported, and hence this process will be very useful to meet the sulphur need in the country.

Several models available for absorption of $\mathrm{SO}_{2}$ are based on lime/limestone slurry [4,5]. Some models are also available in literature regarding the absorption of $\mathrm{SO}_{2}$ in sea water $[6,7]$. A little work has been done on the modeling of wet magnesia FGD slurry. This paper focuses the model for wet magnesia FGD slurry process in terms of the tworeaction-plane model incorporating the solid dissolution promoted by the reactions with $\mathrm{SO}_{2}$ in the liquid film. The objective of this work has been to develop a model of the absorption of $\mathrm{SO}_{2}$ into wet magnesia slurry using an unsteady state mass transfer theory (i.e., Fick's second law) 
and to use the model to quantify the enhancement of the absorption rate of $\mathrm{SO}_{2}$ into a slurry containing small reactive $\mathrm{Mg}(\mathrm{OH})_{2}$ particles.

\section{MODEL DESCRIPTION}

\subsection{Model of absorption through reaction planes}

Regarding the $\mathrm{SO}_{2}$ absorption mechanism into wet magnesia slurry, the following processes can be considered [8]:

$\mathrm{SO}_{2}$ diffusion through the gas film (Diffusion)

$$
\begin{aligned}
& \mathrm{SO}_{2}(\mathrm{~g}) \longrightarrow \mathrm{SO}_{2} \text { (aq.) (Dissolution) } \\
& \mathrm{SO}_{2} \text { (aq.) }+\mathrm{H}_{2} \mathrm{O} \longrightarrow \mathrm{H}_{2} \mathrm{SO}_{3} \text { (Dissociation) } \\
& \mathrm{H}_{2} \mathrm{SO}_{3} \longrightarrow \mathrm{H}^{+}+\mathrm{HSO}_{3}^{-} \text {(Dissociation) } \\
& \mathrm{HSO}_{3}^{-} \longrightarrow \mathrm{H}^{+}+\mathrm{SO}_{3}{ }^{2-} \text { (Dissociation) } \\
& \mathrm{MgO}(\mathrm{s})+\mathrm{H}_{2} \mathrm{O} \longrightarrow \mathrm{Mg}(\mathrm{OH})_{2} \text { (aq.) (Dissolution) } \\
& \mathrm{Mg}(\mathrm{OH})_{2} \text { (aq.) } \longrightarrow \mathrm{Mg}^{2+}+2 \mathrm{OH}^{-} \quad \text { (Dissolution) } \\
& \text { Diffusion of dissolved chemical (Diffusion) } \\
& \text { species in liquid film } \\
& \begin{aligned}
\mathrm{SO}_{2}+2 \mathrm{OH}^{-} \longrightarrow \mathrm{SO}_{3}{ }^{2-}+\mathrm{H}_{2} \mathrm{O} & \text { (Reaction) } \\
\mathrm{SO}_{2}+\mathrm{SO}_{3}^{2-}+\mathrm{H}_{2} \mathrm{O} \longrightarrow 2 \mathrm{HSO}_{3}^{-} & \text {(Reaction) } \\
\mathrm{HSO}_{3}{ }^{-}+\mathrm{OH}^{-} \longrightarrow \mathrm{SO}_{3}{ }^{2-}+\mathrm{H}_{2} \mathrm{O} & \text { (Reaction). }
\end{aligned}
\end{aligned}
$$

Initially, $\mathrm{SO}_{2}$ gas diffuses from bulk of the gas phase to the gas-liquid film, dissolves into the bulk liquid and dissociates. Simultaneously, solid $\mathrm{MgO}$ also dissolves and dissociates. After that, the sulphite and hydroxyl ions react with each other in the liquid film according to (9)-(11). The principal chemical species of the reaction are subjected to acid dissociation; it is necessary to consider the $\mathrm{pH}$ of the absorbent liquid, which largely influences the degree of dissociation.

\subsection{Basic equations}

In the process of $\mathrm{SO}_{2}$ absorption in magnesia slurry with no suspended particles, $\mathrm{HSO}_{3}^{-}$cannot coexist with $\mathrm{OH}^{-}$, so that reaction (9) never takes place directly. The above condition shows that reactions (10) and (11) take place at two different located planes in the two-reaction-plane model. However, in the slurry process, to be considered here, both dissolve $\mathrm{SO}_{2}$ and the $\mathrm{HSO}_{3}^{-}$, to be produced by reaction (10), can react with $\mathrm{OH}^{-}$which is fed by the dissolution of the solid particles in the liquid film. So in this case, dissolved $\mathrm{SO}_{2}$ can be consumed by reactions (9) and (10) simultaneously. The concentration of $\mathrm{SO}_{3}{ }^{2-}$ in the bulk liquid increases as the absorption proceeds. For a saturated solution of magnesia, a plausible sketch of the concentration profile is given in Figure 1(a). When the particles are suspended in the liquid film, the concentration profiles shift as shown in Figure 1(b) [9].
The model considers the presence of 4 basic species: $\mathrm{SO}_{2}, \mathrm{OH}^{-}, \mathrm{SO}_{3^{-}}{ }^{2}$, and $\mathrm{HSO}_{3}^{-}$. The basic equations were derived to form the mass balance of perspective chemical species as shown below. The first terms of (12)-(15) deal with the diffusion of the species according to Fick's second law, while the second term shows the consumption due to their reaction with $\mathrm{Mg}(\mathrm{OH})_{2}$ within the liquid film. The subscripts $A, B, E, F$ in the equations, respectively, indicate the chemical species $\mathrm{SO}_{2}, \mathrm{OH}^{-}, \mathrm{SO}_{3^{-}}{ }^{2}$ and $\mathrm{HSO}_{3}^{-}$.

Liquid film-Region I: it holds that

$$
\begin{aligned}
& D_{A} \cdot \frac{d^{2}}{d z^{2}} C_{A} \\
& -\frac{K_{s} \cdot\left[1+2 \cdot\left(\left(C_{A} \cdot D_{A}\right) / C_{B s} \cdot D_{B}\right)\right] \cdot A_{p} \cdot C_{B s}}{2}=0 \\
& D_{F} \cdot \frac{d^{2}}{d z^{2}} C_{F}-K_{s} \cdot\left(1+\frac{C_{F} \cdot D_{F}}{C_{B s} \cdot D_{B}}\right) \cdot A_{p} \cdot C_{B s}=0
\end{aligned}
$$

Liquid film-Region II: it holds that

$$
\begin{gathered}
D_{E} \frac{d^{2}}{d z^{2}} C_{E}-K_{s} \cdot\left(1+\frac{C_{F} \cdot D_{F}}{C_{B s} \cdot D_{B}}\right) \cdot A_{p} \cdot C_{B S}=0, \\
D_{F} \cdot \frac{d^{2}}{d z^{2}} C_{F}-K_{s} \cdot\left(1+\frac{C_{F} \cdot D_{F}}{C_{B s} \cdot D_{B}}\right) \cdot A_{p} \cdot C_{B s}=0 .
\end{gathered}
$$

Liquid film-Region III: it holds that

$$
\begin{gathered}
D_{B} \cdot \frac{d^{2}}{d z^{2}} C_{B}+K_{s} \cdot A_{P} \cdot\left(C_{B s}-C_{B}\right)=0, \\
D_{E} \cdot \frac{d^{2}}{d z^{2}} C_{E}=0 .
\end{gathered}
$$

The boundary conditions imposed are as follows:

$$
\begin{aligned}
& \text { at } z=0, \quad C_{A}=C_{A i} \frac{d}{d z} C_{F}=0, \\
& \text { at } z=z_{1}, \quad C_{A}=C_{E}=0, \quad C_{F}=C_{F}^{*}, \\
& -D_{F} \cdot \frac{d}{d z} C_{F}=D_{E} \cdot \frac{d}{d z} C_{E} \\
& -\left.D_{F} \cdot \frac{d}{d z} C_{F}\right|_{z=z_{1}-}+\left.D_{F} \cdot \frac{d}{d z} C_{F}\right|_{z=z_{1}+}=\left.2 \cdot D_{E} \cdot \frac{d}{d_{z}} C_{E}\right|_{z=z_{1}+} \\
& \text { at } z=z_{2}, \quad C_{B}=C_{F}=0, \quad C_{E}=C_{E}^{*}, \\
& D_{B} \cdot \frac{d}{d z} C_{B}=-D_{F} \cdot \frac{d}{d z} C_{F} \\
& \text { at } z=z_{L}, \quad C_{B}=C_{B s}, \quad C_{E}=C_{E 0}=0 .
\end{aligned}
$$

Here, $C_{E}{ }^{*}$ and $C_{F}{ }^{*}$ represent the concentrations of $E$ at $z_{2}$ and $F$ at $z_{1}$, respectively. 


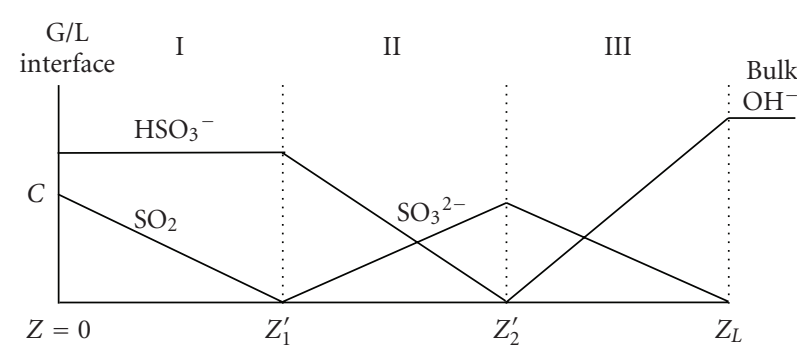

(a)

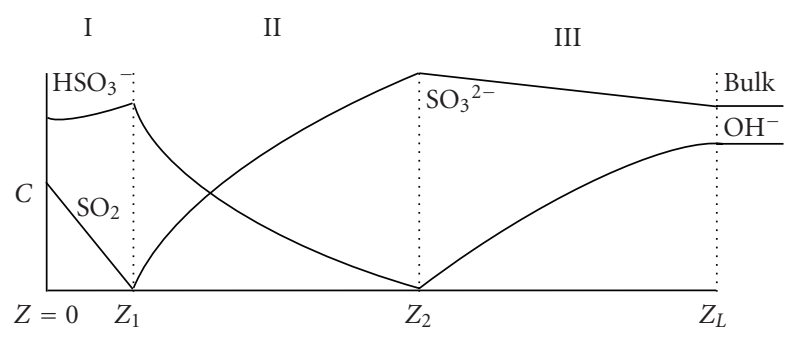

(b)

FIGURE 1: Concentration profile for $\mathrm{SO}_{2} / \mathrm{Mg}(\mathrm{OH})_{2}$ slurry: (a) no suspended solids, (b) in the presence of suspended solids.

The mass balance equations in the dimensionless form reduce to the following.

Region I:

$$
\begin{gathered}
\frac{d^{2}}{d x^{2}} Y_{A}-N \cdot Y_{A}=\frac{N}{2 \cdot r_{A} \cdot q_{A}}, \\
\frac{d^{2}}{d x^{2}} Y_{F}-N \cdot Y_{F}=\frac{N}{r_{F}},
\end{gathered}
$$

Region II:

$$
\begin{gathered}
\frac{d^{2}}{d x^{2}} Y_{E}-\frac{N \cdot r_{F}}{r_{E}} \cdot Y_{E}=\frac{-N}{r_{E}}, \\
\frac{d^{2}}{d x^{2}} Y_{F}-N \cdot Y_{F}=\frac{N}{r_{F}}
\end{gathered}
$$

Region III:

$$
\begin{gathered}
\frac{d^{2}}{d x^{2}} Y_{B}-N \cdot Y_{B}=-N, \\
\frac{d^{2}}{d x^{2}} Y_{E}=0
\end{gathered}
$$

subject to

$$
\begin{aligned}
& x=0 ; \quad Y_{A}=1, \quad \frac{d Y_{F}}{d x}=0, \\
& x=x_{1} ; \quad Y_{A}=Y_{E}=0, \quad Y_{F}=Y_{F}{ }^{*}, \\
& -r_{A} \cdot q_{A} \cdot \frac{d}{d x} Y_{A}=r_{E} \cdot \frac{d}{d x} Y_{E}, \\
& -\left.r_{F} \cdot \frac{d}{d x} Y_{F}\right|_{\left(X=X_{1}^{-}\right)}+\left.r_{F} \cdot \frac{d}{d x} Y_{F}\right|_{\left(X=X_{1}{ }^{+}\right)} \\
& =\left.2 \cdot r_{E} \cdot \frac{d}{d x} Y_{E}\right|_{\left(X=X_{1}{ }^{+}\right)}, \\
& x=x_{2} ; \quad Y_{B}=Y_{F}=0, \quad Y_{E}=Y_{E}^{*}, \\
& \frac{d}{d x} Y_{B}=-r_{F} \cdot \frac{d}{d x} Y_{F} \\
& =\left.r_{E} \cdot \frac{d}{d x} Y_{E}\right|_{\left(X=X_{2}{ }^{-}\right)}-\left.r_{E} \cdot \frac{d}{d x} Y_{E}\right|_{\left(X=X_{2}{ }^{+}\right)}, \\
& x=1 ; \quad Y_{B}=1, \quad Y_{E}=0 .
\end{aligned}
$$

When the concentration of gaseous species is extremely low and the enhancement factor for the solid dissolution can be regarded as unity, (18)-(21) are simplified as follows:

Region I:

$$
\begin{gathered}
\frac{d^{2}}{d x^{2}} Y_{A}=\frac{N}{2 \cdot r_{A} \cdot q_{A}}, \\
\frac{d^{2}}{d x^{2}} Y_{F}=\frac{N}{r_{F}}
\end{gathered}
$$

Region II:

$$
\begin{gathered}
\frac{d^{2}}{d x^{2}} Y_{E}=\frac{N}{r_{E}}, \\
\frac{d^{2}}{d x^{2}} Y_{F}=\frac{N}{r_{F}},
\end{gathered}
$$

Equations (24)-(27), (22) give the enhancement factor as

$$
E=\frac{N \cdot x_{1}}{4 \cdot r_{A} \cdot q_{A}}+\frac{1}{x_{1}} .
$$

$E_{0}$ represents the enhancement factor for a clear solution saturated with $\mathrm{Mg}(\mathrm{OH})_{2}$ and is defined by

$$
E_{0}=1+\frac{1}{2 \cdot r_{A} \cdot q_{A}}
$$

The dimensionless positions of two reaction planes, $x_{1}$ and $x_{2}$, can be determined by the following equations [10]:

$$
\begin{aligned}
&\left(\frac{x_{2}}{2}-\frac{x_{1}}{4}\right) \cdot N \frac{r_{A} q_{A}}{x_{1}}+\frac{1-x_{2}}{1-x_{1}} \\
& \cdot {\left[\frac{\sqrt{N}}{\tanh \left[\sqrt{N} \cdot\left(1-x_{2}\right)\right]}+\frac{N \cdot\left(x_{2}-x_{1}\right)}{2}\right]=0, } \\
&\left(\frac{3}{2} \cdot x_{1}-x_{2}\right) \cdot N+\frac{2 x_{2}-x_{1}-1}{1-x_{2}} \\
& \cdot\left[\frac{r_{A} \cdot q_{A}}{x_{1}}-\left(\frac{x_{2}}{2}-\frac{x_{1}}{4}\right) \cdot N\right]=0 .
\end{aligned}
$$

\section{RESULT AND DISCUSSION}

\subsection{Model parameter estimation}

In order to have the numerical results of the above model regarding enhancement factor, it is necessary to know the 

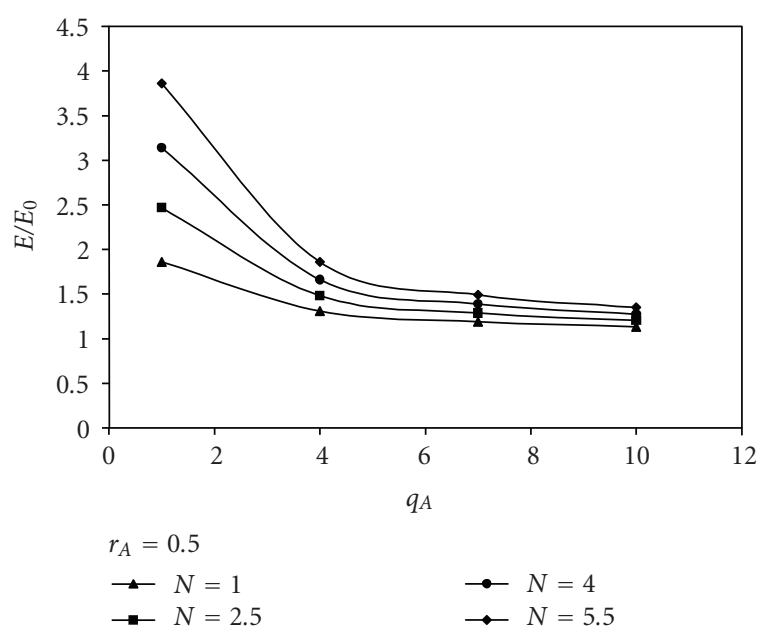

(a)
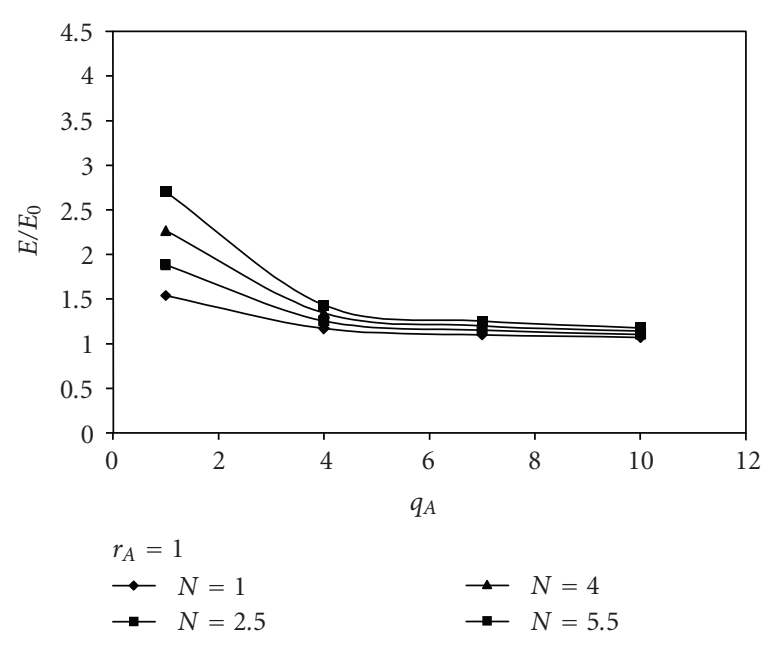

(b)

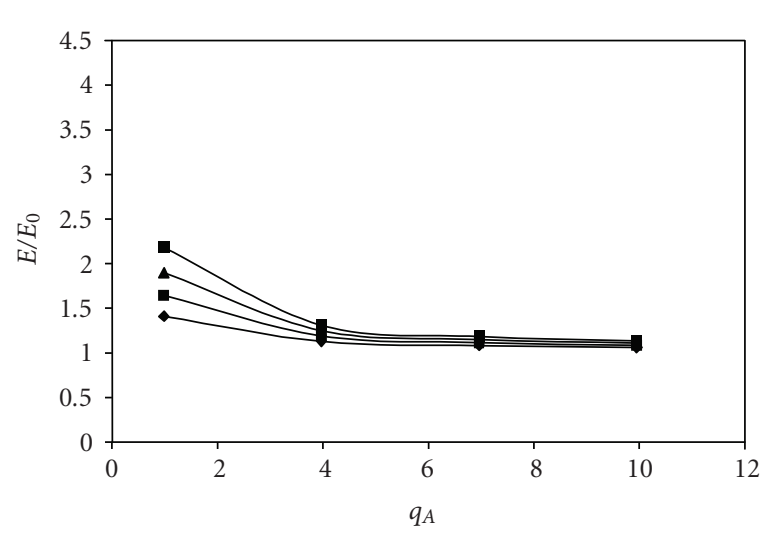

$$
\begin{array}{ll}
r_{A}=1.5 & \\
\rightarrow-N=1 & \rightarrow-N=4 \\
\rightarrow N=2.5 & \rightarrow-N=5.5
\end{array}
$$

(c)

Figure 2: Enhancement factors as a function of $q_{A}$ for the $\mathrm{SO}_{2}$ $\mathrm{Mg}(\mathrm{OH})_{2}$ slurry system. Enhancement factors as a function of $q_{\mathrm{A}}$ for the $\mathrm{SO}_{2}-\mathrm{Mg}(\mathrm{OH})_{2}$ slurry system. Enhancement factors as a function of $q_{A}$ for the $\mathrm{SO}_{2}-\mathrm{Mg}(\mathrm{OH})_{2}$ slurry system.

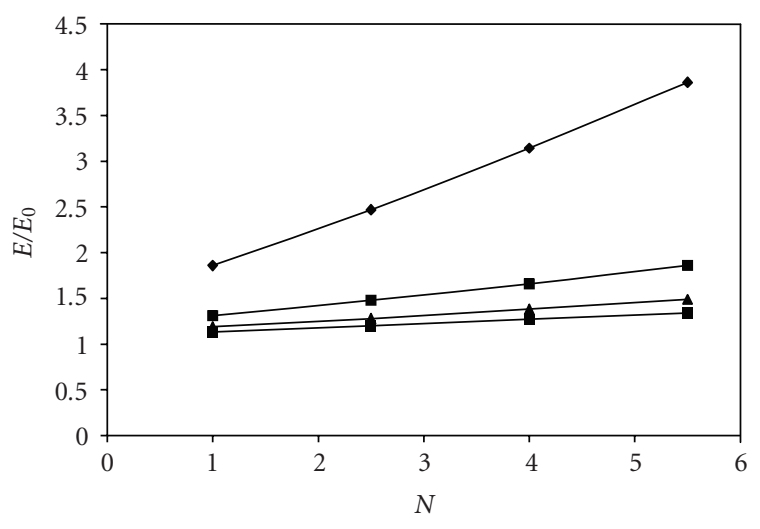

$$
\begin{array}{ll}
r_{A}=0.5 & \\
\rightarrow-q_{A}=1 & \rightarrow q_{A}=7 \\
\rightarrow-q_{A}=4 & \rightarrow q_{A}=10
\end{array}
$$

(a)

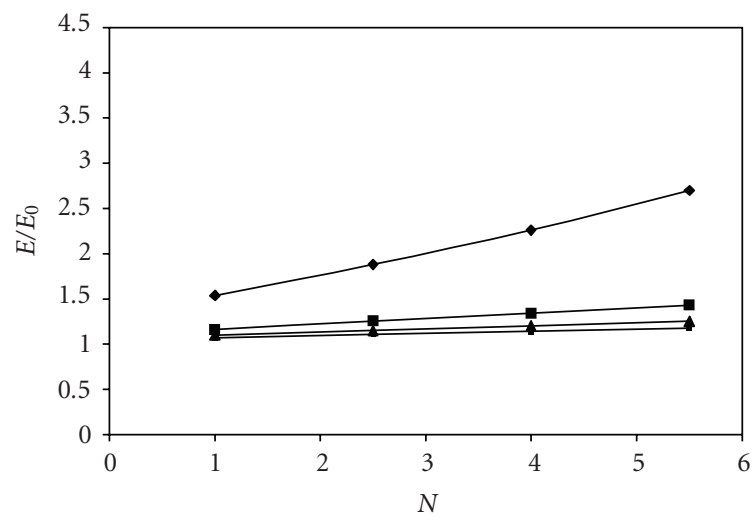

$$
\begin{array}{ll}
r_{A}=1 & \\
\rightarrow-q_{A}=1 & \rightarrow q_{A}=7 \\
\rightarrow-q_{A}=4 & \rightarrow q_{A}=10
\end{array}
$$

(b)

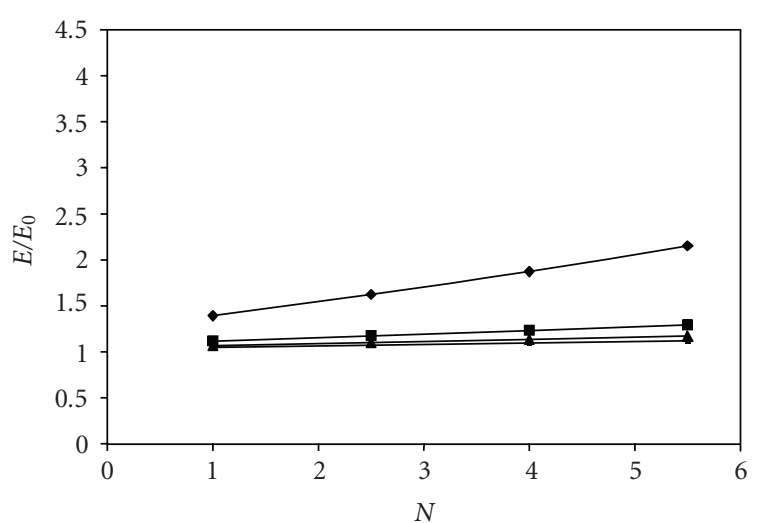

$$
\begin{array}{ll}
r_{A}=1.5 & \\
\rightarrow q_{A}=1 & \rightarrow q_{A}=7 \\
\rightarrow q_{A}=4 & \rightarrow q_{A}=10
\end{array}
$$

(c)

FIgURE 3: Enhancement factors as a function of $\mathrm{N}$ for the $\mathrm{SO}_{2}-$ $\mathrm{Mg}(\mathrm{OH})_{2}$ slurry system. Enhancement factors as a function of $\mathrm{N}$ for the $\mathrm{SO}_{2}-\mathrm{Mg}(\mathrm{OH})_{2}$ slurry system. Enhancement factors as a function of $\mathrm{N}$ for the $\mathrm{SO}_{2}-\mathrm{Mg}(\mathrm{OH})_{2}$ slurry system. 


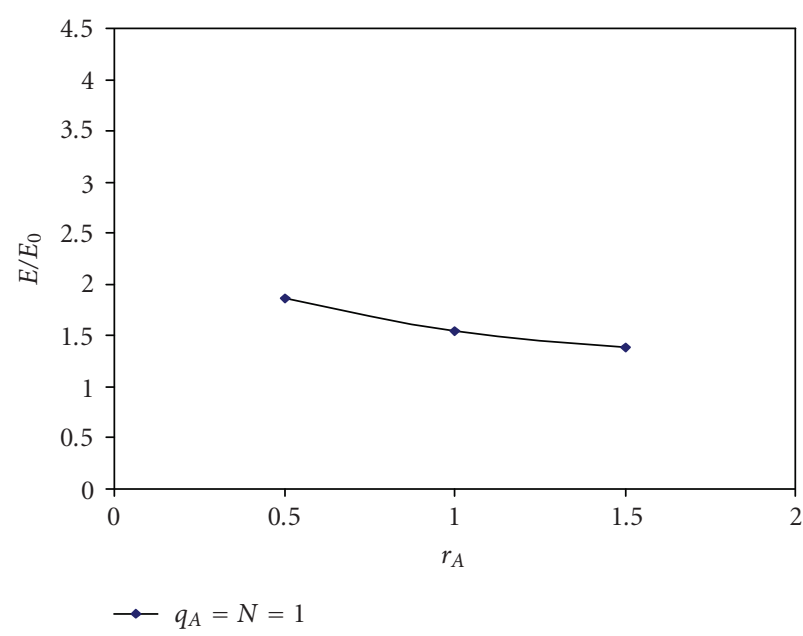

FIgURE 4: Enhancement factor as a function of $r_{A}$ for $\mathrm{SO}_{2}-$ $\mathrm{Mg}(\mathrm{OH})_{2}$ slurry system.

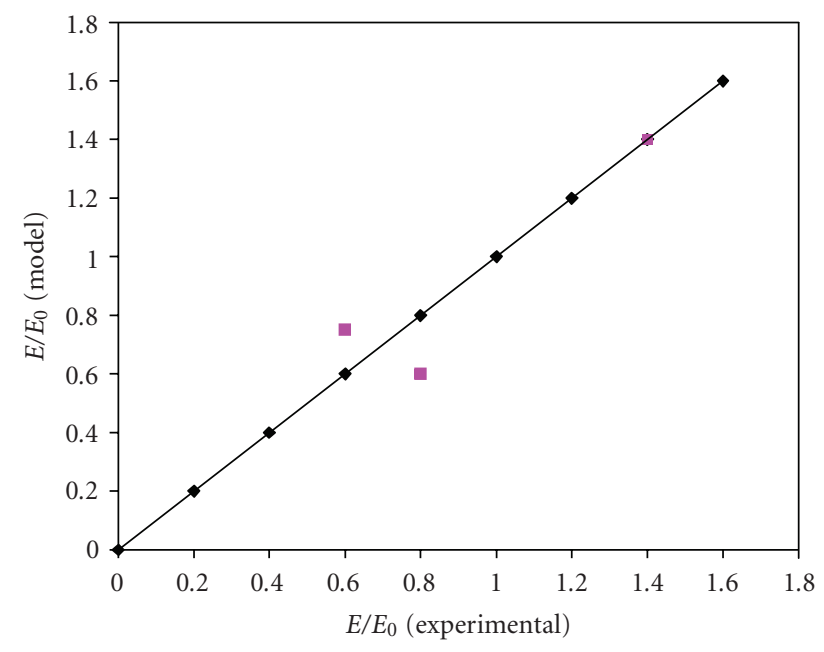

- Dagaonkar et al. (2001)

- Sada et al. (1981)

Figure 5: Comparison between experimental values available in literature and model values of the enhancement factor for the $\mathrm{SO}_{2}-$ $\mathrm{Mg}(\mathrm{OH})_{2}$ slurry system.

values of the dimensionless parameters $r_{A}, q_{A}$, and $N$. The values of $r_{A}, q_{A}$, and $N$ have been considered as same as the experimental data by various workers available in the literature. To show the contribution of the presence of the solids to the absorption rate, the ratio of enhancement factor into the slurry to that into saturated solution $\left(E / E_{0}\right)$ is plotted against $q_{A}$ in Figures $2(\mathrm{a})-2(\mathrm{c})$. The ratio $E / E_{0}$ represents the degree of enhancement owing to the presence of solid particles in the slurry. The parameter regarding the solid dissolution, $N$, is fixed (1.0-5.5), and the parameter $r_{A}$ regarding the ratio of diffusivity of $\mathrm{SO}_{2}$ to that of liquid is also fixed (0.5-1.5). From the figures, it is observed that $E / E_{0}$ initially decreases with the increase in $q_{A}$, and then it is almost independent of $q_{A}$. It indicates that when $C_{A i}$ is kept constant, the enhancement in gas absorption rate due to the presence of the suspended reactant particles is almost independent of the gas-phase concentration. The influences in gas-phase concentration and $N$ improve the absorption characteristics.

To show the effect of solid dissolution $(N)$ on absorption rate, the ratio of enhancement factor $\left(E / E_{0}\right)$ is plotted against $N$ (see Figures 3(a)-3(c)) for constant value of $r_{A}$. It is seen from the figures that the difference of the enhancement factors is very small with the variation of $q_{A}$ from 4 to 10 , and $E / E_{0}$ is almost independent on $N$.

For the contribution of $r_{A}$ on absorption rate, a plot is drawn between $E / E_{0}$ versus $r_{A}$ by considering both $q_{A}$ and $N$ to be the same as shown in Figure 4. In this case, the diffusivity of $\mathrm{SO}_{2}$ in the slurry was assumed to be the same as that of the pure water, and the concentration of $\mathrm{SO}_{2}$ at the gas-liquid interface was assumed to be equal to the solubility of the hydroxide in the water. Under these circumstances, Figure 4 shows that $E / E_{0}$ decreases as $r_{A}$ increases.

\subsection{Model verification}

Figure 5 shows the comparison between the experimental values available in literature $[3,11]$ and the values (obtained from model) of enhancement factor owing to the presence of solid particles for magnesium hydroxide in the slurry. It is evident that the experimental values available in literature and the model values are in good agreement.

\section{CONCLUSION}

In spite of noticeable progress in conventional flue gas desulphurization (FGD) process development, claims for more efficient, more economic, and nonpollutant technological innovations become more and more important. The new technology essentially is the wet magnesia FGD process which is technically and economically competitive with once-through FGD process. In this article, a model based on Fick's Second law has been developed for dynamic absorption rate of sulphur dioxide into $\mathrm{Mg}(\mathrm{OH})_{2}$ slurry with the help of two reaction planes.

Numerical solutions for the absorption of $\mathrm{SO}_{2}$ in aqueous slurries of $\mathrm{Mg}(\mathrm{OH})_{2}$ are presented in Figures 25. The dissolution of fine solid $\mathrm{Mg}(\mathrm{OH})_{2}$ particles has significant effect on enhancement factor which contributes to the absorption rate of $\mathrm{SO}_{2}$ from bulk of the gas phase to the liquid. It is efficient to understand that the reaction of $\mathrm{SO}_{2}$ with accumulated species $\mathrm{SO}_{3}{ }^{2-}$ promotes the absorption rate. The theoretical enhancement factors obtained from present model were compared well with experimental data available in literature. The model presented can be applied to any highly complicated reactive absorption processes. It should be stressed that analytical approximations are often oversimplified and cannot be expected to predict the absorption rates for a wide range of conditions. 


\section{LIST OF SYMBOLS}

$A_{p}: \quad$ Surface area of solid particles $=6 \cdot w / \rho \cdot d_{p} \mathrm{~m}^{2} / \mathrm{m}^{3}$ dispersion

C: $\quad$ Concentration in liquid phase $\left(\mathrm{kmol} / \mathrm{m}^{3}\right)$

$D: \quad$ Diffusivity in liquid phase, $\mathrm{m}^{2} / \mathrm{s}$

$d_{p}: \quad$ Average diameter of the solid particles, $\mathrm{m}$

E: $\quad$ Enhancement factor

$k_{s}: \quad$ Mass transfer coefficient for solid dissolution, $\mathrm{m} / \mathrm{s}$

$N: \quad$ Solid dissolution parameter $=k_{s} \cdot A_{p} \cdot\left(Z_{L}\right)^{2} / D_{B}$.

$q_{A}: \quad C_{A i} / C_{B s}$

$r_{1}: \quad\left(D_{I} / D_{B}\right)(I=A, B, E$ and $F)$

$x$ : $\quad$ Dimensionless distance from gas-liquid interface $=$ $Z / Z_{L}$

$x_{1}: \quad Z_{1} / Z_{L}$

$x_{2}: \quad Z_{2} / Z_{L}$

$Y: \quad$ Concentration in the liquid phase relative to that at the gas-liquid interface or at the solid surface

$z_{1}, z_{1}$ : Position of one reaction plane as shown in Figure $1(\mathrm{~m})$

$z_{2}, z_{2}$ : Position of another reaction plane as shown in Figure 1, m

$z_{L}$ : Thickness of the liquid film (gas absorption), $\mathrm{m}$

\section{GREEK SYMBOLS}

$\rho$ : Analysis of variance

\section{SUBSCRIPTS}

[4] A. Lancia, D. Musmarra, and F. Pepe, "Modeling of $\mathrm{SO}_{2}$ absorption into limestone suspensions," Industrial and Engineering Chemistry Research, vol. 36, no. 1, pp. 197-203, 1997.

[5] C. Brogren and H. T. Karlsson, "Modeling the absorption of $\mathrm{SO}_{2}$ in a spray scrubber using the penetration theory," Chemical Engineering Science, vol. 52, no. 18, pp. 3085-3099, 1997.

[6] J. Rodríguez-Sevilla, M. Álvarez, M. C. Díaz, and M. C. Marrero, "Absorption equilibria of dilute $\mathrm{SO}_{2}$ in seawater," Journal of Chemical and Engineering Data, vol. 49, no. 6, pp. 1710-1716, 2004.

[7] G. Al-Enezi, H. Ettouney, H. El-Dessouky, and N. Fawzi, "Solubility of sulfur dioxide in seawater," Industrial and Engineering Chemistry Research, vol. 40, no. 5, pp. 1434-1441, 2001.

[8] M. K. Mondal, "Absorption equilibria of dilute sulphur dioxide in $\mathrm{Mg}(\mathrm{OH})_{2}$ slurry," Fluid Phase Equilibria, vol. 262, no. 1-2, pp. 111-120, 2007.

[9] E. Sada, H. Kumazawa, Y. Sawada, and I. Hashizume, "Kinetics of absorptions of lean sulfur dioxide into aqueous slurries of calcium carbonate and magnesium hydroxide," Chemical Engineering Science, vol. 36, no. 1, pp. 149-155, 1981.

[10] E. Sada, H. Kumazawa, and M. A. Butt, "Single and simultaneous absorptions of lean $\mathrm{SO}_{2}$ and $\mathrm{NO}_{2}$ into aqueous slurries of $\mathrm{Ca}(\mathrm{OH})_{2}$ or $\mathrm{Mg}(\mathrm{OH})_{2}$ particles," Journal of Chemical Engineering of Japan, vol. 12, no. 2, pp. 111-117, 1979.

[11] E. Sada, H. Kumazawa, and M. A. Butt, "Removal of dilute sulfur dioxide by aqueous slurries of magnesium hydroxide particles," Chemical Engineering Science, vol. 32, no. 8, pp. 972 974, 1977.
A: $\mathrm{SO}_{2}$
$B: \mathrm{OH}^{-}$
$\mathrm{E}: \mathrm{SO}_{3}{ }^{2-}$
F: $\mathrm{HSO}_{3}^{-}$
I: At the gas-liquid interface
$S$ : At the surface of solid particle
0 : In the bulk of the liquid

\section{ACKNOWLEDGMENT}

M. K. Mondal gratefully acknowledges Banaras Hindu University for necessary support.

\section{REFERENCES}

[1] F. Tomás-Alonso, "A new perspective about recovering $\mathrm{SO}_{2}$ offgas in coal power plants: energy saving. Part II. Regenerable dry methods," Energy Sources, vol. 27, no. 11, pp. 1043-1049, 2005.

[2] S. Ebrahimi, C. Picioreanu, R. Kleerebezem, J. J. Heijnen, and M. C. M. van Loosdrecht, "Rate-based modelling of $\mathrm{SO}_{2}$ absorption into aqueous $\mathrm{NaHCO}_{3} / \mathrm{Na}_{2} \mathrm{CO}_{3}$ solutions accompanied by the desorption of $\mathrm{CO}_{2}$," Chemical Engineering Science, vol. 58, no. 16, pp. 3589-3600, 2003.

[3] M. V. Dagaonkar, A. A. C. M. Beenackers, and V. G. Pangarkar, "Enhancement of gas-liquid mass transfer by small reactive particles at realistically high mass transfer coefficients: absorption of sulfur dioxide into aqueous slurries of $\mathrm{Ca}(\mathrm{OH})_{2}$ and $\mathrm{Mg}(\mathrm{OH})_{2}$ particles," Chemical Engineering Journal, vol. 81, no. 1-3, pp. 203-212, 2001. 

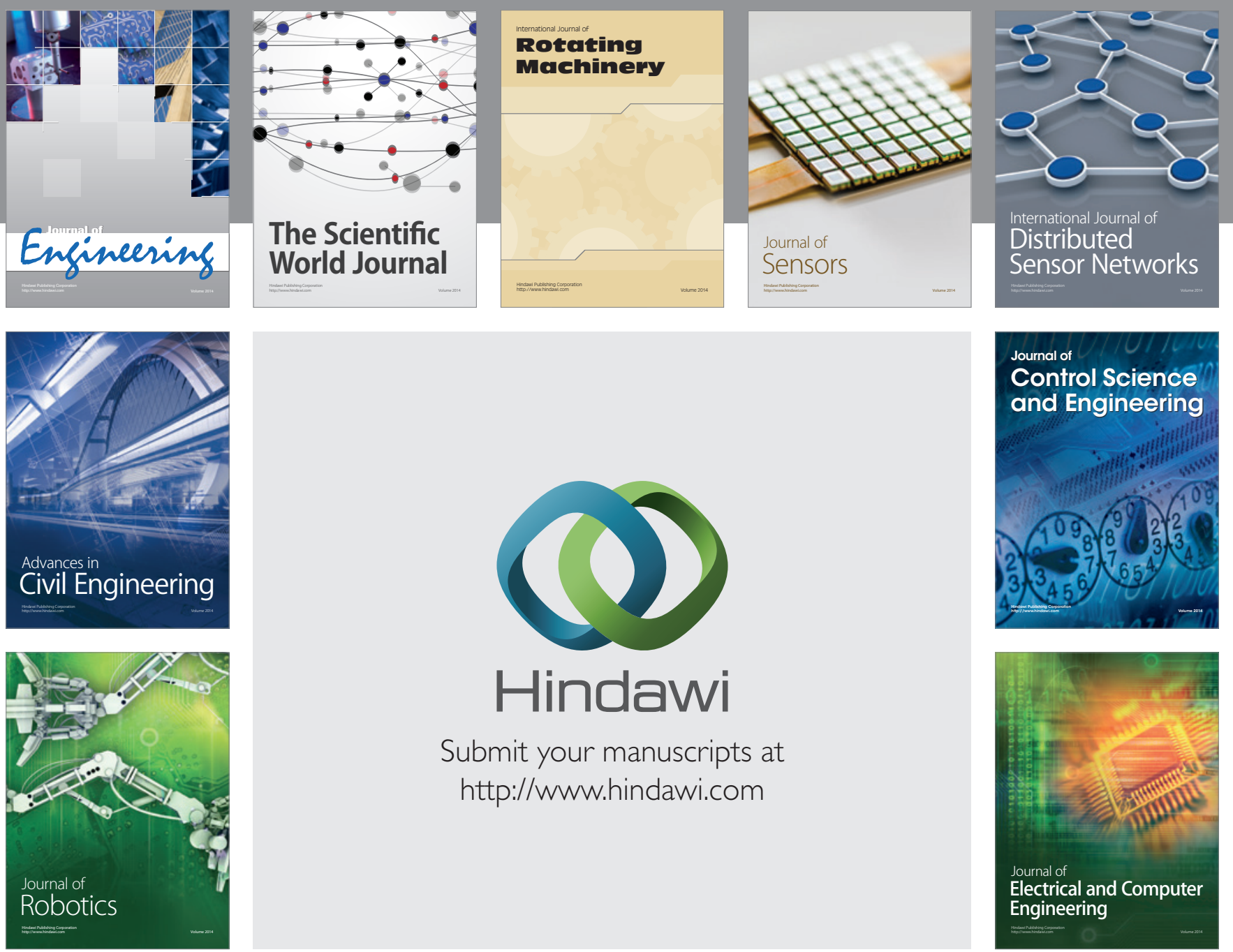

Submit your manuscripts at

http://www.hindawi.com
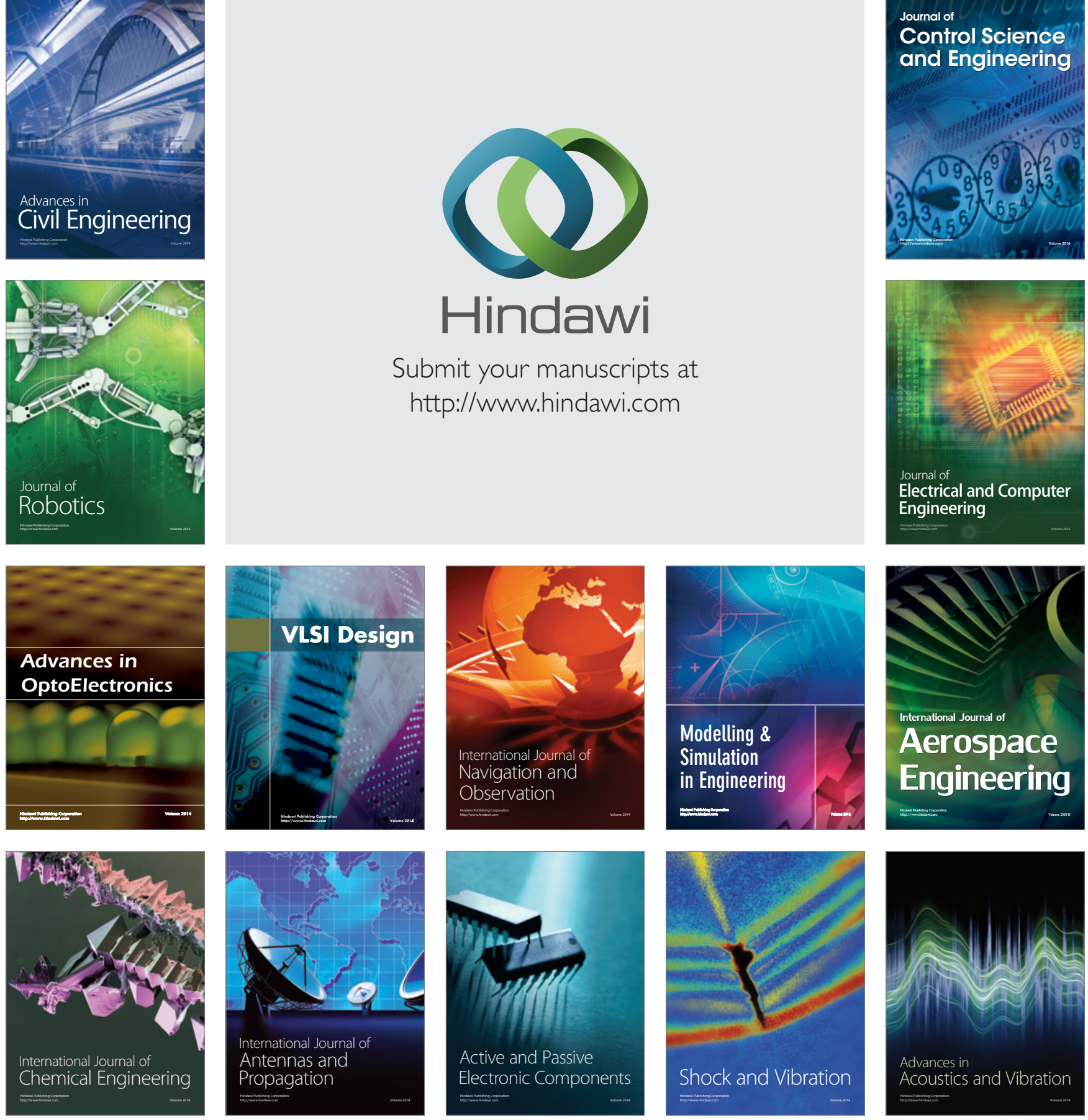